\section{Intoxicações e uso de pesticidas por agricultores do Município de Paty do Alferes, Rio de Janeiro, Brasil}

\author{
Pesticide use and poisoning among farmers \\ from the county of Paty do Alferes, \\ Rio de Janeiro, Brazil
}

Isabella Fernandes Delgado 1

Francisco José Roma Paumgartten 2

\footnotetext{
1 Departamento de

Farmacologia e Toxicologia Instituto Nacional de Controle de Qualidade em Saúde, Fundação Oswaldo Cruz, Rio de Janeiro, Brasil.

2 Laboratório de Toxicologia Ambiental, Departamento de Ciências Biológicas, Escola Nacional de Saúde Pública Fundação Oswaldo Cruz, Rio de Janeiro, Brasil.

Correspondência Francisco José Roma Paumgartten Laboratório de Toxicologia Ambiental, Departamento de Ciências Biológicas, Escola Nacional de Saúde Pública, Fundação Oswaldo Cruz. Rua Leopoldo Bulhões 1480 , Rio de Janeiro, $R J$ 21041-210, Brasil. paum@ensp.fiocruz.br
}

\section{Abstract}

This survey is part of a more comprehensive study on the health consequences of pesticide exposure. In the county (municipality) of Paty do Alferes, Rio de Janeiro State, Brazil, 55 agricultural workers were interviewed on the use of pesticides, use of personal protective equipment, data on health status, and symptoms related to pesticide exposure, disposal of agrochemical containers, and technical assistance. The most widely used pesticides were insecticides such as abamectin, organophosphate compounds, and pyrethroids, and fungicides such as mancozeb, chlorothalonil, and copper products. As a rule, pesticides are handled carelessly, and 92\% of workers involved in the mixing, loading, and spraying of insecticides and fungicides used no protective clothing or equipment whatsoever. Some $62 \%$ of workers reported at least one illness associated with mixing or spraying pesticides. The most frequently reported symptoms were headache, nausea, vomiting, dizziness, skin irritation, and blurred vision, and $21 \%$ of affected workers required medical care. In more than half (51\%) of the cases, workers reported using organophosphate insecticides from toxicological class I when they felt sick.

Occupational Exposure; Pesticides; Organophosphorus Compounds; Occupational Health

\section{Introdução}

O risco de efeitos adversos à saúde humana relacionados ao uso de pesticidas depende fundamentalmente do perfil toxicológico do produto, do tipo e da intensidade da exposição experimentada pelos indivíduos e da susceptibilidade da população exposta. A exposição individual torna-se menor, e conseqüentemente o uso de pesticidas mais seguro, à medida que procedimentos de proteção são adotados e as regras de segurança obedecidas.

Há indícios de que, nos países em desenvolvimento, o uso indevido de agroquímicos representa um sério problema de saúde pública, mas esta questão ainda não foi devidamente estudada 1 . O consumo de pesticidas tem crescido rapidamente no Terceiro Mundo e em países emergentes 2 , mas na maioria dos casos não existe controle eficaz sobre a venda e uso destes produtos, os equipamentos de proteção não são usados rotineiramente, não há monitoramento da exposição ocupacional e o diagnóstico e tratamento dos casos de intoxicação são falhos 3 .

A incidência de intoxicações agudas por pesticidas é consideravelmente maior nos países em desenvolvimento do que nos industrializados. No Reino Unido, por exemplo, são relatados anualmente menos de vinte casos de intoxicações ocupacionais a organofosforados 4, enquanto no Sri Lanka foram registradas 100 
mil internações hospitalares/ano e mil mortes/ ano em decorrência do uso indevido de pesticidas 5 . Alguns autores estimam que a incidência de intoxicações por pesticidas nos países menos desenvolvidos seja até 13 vezes maior do que a observada nos países industrializados 3 .

Embora se tenha uma consciência difusa do problema, há relativamente poucos estudos sobre as condições em que ocorre a exposição de agricultores brasileiros a pesticidas 6,7,8,9,10,11.

O presente trabalho é parte de um estudo maior, voltado para a avaliação do impacto do uso de pesticidas sobre a saúde de trabalhadores rurais, realizado da região de Paty do Alferes, Rio de Janeiro. Este município tem grande parte da sua população vivendo na área rural, é um dos maiores produtores de tomate e olerícolas do Estado 12, e usa intensamente pesticidas, como sugerem dados da Fundação Instituto Brasileiro de Geografia e Estatística (IBGE), do início da década de 1990 13. Neste trabalho, após discutirmos o perfil do informante, avaliamos os pesticidas usados na região, o emprego de equipamentos de proteção e medidas de higiene, a ocorrência de sintomas de intoxicação durante o trabalho, o destino dado às embalagens vazias, e o tipo de orientação e assistência técnica recebida pelos usuários destes produtos.

\section{Material e métodos}

Os dados foram obtidos por meio da aplicação de um questionário com 85 itens contendo perguntas sobre os seguintes aspectos: (1) dados gerais do informante (escolaridade, situação na lavoura, higiene, consumo de álcool e fumo), (2) uso de pesticidas (natureza do produto, quantidade, indicações e forma de uso), (3) uso de equipamentos de proteção individual e medidas de higiene, (4) morbidade referida (estado geral de saúde, episódios de intoxicação e sintomas associados pelo entrevistado à exposição a pesticidas), (5) destino das embalagens vazias e (6) orientação e assistência técnica recebida. Todas as entrevistas foram realizadas no local de trabalho (lavoura), duraram em média 45 minutos e foram gravadas em fita magnética. A localização de cada lavoura foi registrada com o auxílio de um localizador por satélite (Global Positioning System, Accuner Sport - Eagle Mod. 506989). Ao final da entrevista foram visitados os locais de armazenamento de pesticidas e equipamentos de pro- teção e de descarte das embalagens vazias. Após uma etapa inicial de aperfeiçoamento, incluindo um teste de campo, o questionário passou por uma fase de validação (pré-teste), onde 18 agricultores das localidades de Palmares, Horizonte, Coqueiros e Guaribu (Paty do Alferes) foram entrevistados. Em seguida, iniciou-se a aplicação de questionários na microbacia do Córrego do Saco - Rio Ubá, onde procurou-se entrevistar todos os líderes ou "donos de terra" de todas as lavouras ativas na região, no período de julho a outubro de 1997. A população estudada encerra 55 agricultores, concentrados em três localidades (Campo Verde, Bela Vista e Caetés) do Município de Paty do Alferes (22015' 22o30' Sul e 43o16'-41o31' Oeste) localizado na Serra do Mar a aproximadamente $130 \mathrm{~km}$ da cidade do Rio de Janeiro, no Estado do Rio de Janeiro. Este município compreende uma área total de $320 \mathrm{~km}^{2}$, com densidade demográfica de 71,92 habitantes $/ \mathrm{km}^{2}$. Essa é uma região de clima tropical, com temperatura média anual de $20 \circ \mathrm{C}$ e $610 \mathrm{~m}$ de altitude. Há décadas a atividade econômica principal da maioria de seus 22.500 habitantes é a agropecuária, seguida pelo comércio e o turismo. Dentre as lavouras encontradas, o tomate se destaca como a de maior produção, constituindo o suporte financeiro dos produtores do município. Seguem, em importância de produção, as lavouras de repolho e pimentão. Este estudo foi aprovado pelo Comitê de Ética em Pesquisa da Fundação Oswaldo Cruz.

\section{Resultados e discussão}

Os dados aqui apresentados constituem um levantamento dos produtos usados na região, das medidas de proteção individual adotadas, da armazenagem e destino das embalagens vazias, da assistência técnica recebida e dos sintomas que os agricultores associam à exposição ocupacional a pesticidas.

\section{Caracterização da amostra}

Os dados relacionados à caracterização da amostra estão resumidos na Tabela 1. Cinqüenta e cinco trabalhadores rurais foram entrevistados, sendo 52 homens e três mulheres. A classificação dos entrevistados segundo a faixa etária foi a seguinte: $4 \%$ têm até 20 anos de idade, $60 \%$ entre 21 e 40 anos, $29 \%$ entre 41 e 60 anos e $7 \%$ mais de 60 anos. Dos agricultores, 
$27 \%$ nunca freqüentaram a escola. Dentre aqueles que freqüentaram a escola, $8 \%$ estudaram apenas até a primeira série, $28 \%$ até a segunda, $28 \%$ até a terceira, $23 \%$ até a quarta, $2 \%$ até a quinta, $2 \%$ até a sexta, $2 \%$ até a sétima série e $2 \%$ até a oitava série do primeiro grau. A escolaridade máxima dos entrevistados foi o segundo grau incompleto (5\%). Dos entrevistados, $40 \%$ são meeiros (i.e. indivíduos que plantam em terreno alheio, repartindo o resultado das plantações com o proprietário), 38\% donos da terra onde trabalham, $7 \%$ arrendatários, $7 \%$ ocupantes (terra cedida, ocupada ou emprestada), $4 \%$ são empregados, $2 \%$ arrendatários e/ ou donos da terra e $2 \%$ sócios da lavoura. A classificação de acordo com o tempo de trabalho na lavoura foi a seguinte: $11 \%$ até 10 anos, $22 \%$ entre 11 e 20 anos, $31 \%$ entre 21 e $30,20 \%$ entre 31 e $40,11 \%$ entre 41 e 50 e $5 \%$ entre 51 e 60 anos. Todos os agricultores entrevistados relataram usar regularmente pesticidas nas suas lavouras.

\section{Pesticidas usados na região}

Os pesticidas citados pelos entrevistados e encontrados nas visitas feitas aos locais de armazenamento estão listados nas Tabelas 2 e 3. Foram encontrados, entre inseticidas, fungicidas e acaricidas, 36 produtos comerciais: 8 da classe I (extremamente tóxico), 12 da classe II (altamente tóxico), 9 da III (medianamente tóxico) e 7 da IV (pouco tóxico), segundo a classificação toxicológica do Ministério da Agricultura/Ministério da Saúde, baseada no Decreto 98.816/90 de 11 de janeiro de 1990, que regulamenta a Lei 7.802/89. Três produtos da classe toxicológica I estão entre os cinco que foram encontrados mais freqüentemente na região: i.e. Tamaron ${ }^{\circledR}$ em $53 \%$, Daconil ${ }^{\circledR}$ em $47 \%$ e Ortho Hamidop ${ }^{\circledR}$ em $35 \%$ das 55 lavouras visitadas. Não foram encontrados herbicidas nas 55 lavouras visitadas.

\section{Preparo e aplicação dos pesticidas}

Em 100\% das propriedades visitadas, observamos que os agroquímicos são diluídos em tanques ou tambores na própria lavoura. Dos entrevistados, $72 \%$ utilizam pulverizador estacionário motorizado e $15 \%$ pulverizador estacionário manual para aplicação dos pesticidas. Somente $8 \%$ utilizam pulverizador costal. Cerca de 5\% dos entrevistados não estavam envolvidos na aplicação de pesticidas.
Tabela 1

Caracterização da amostra de trabalhadores agrícolas estudada no Município de Paty do Alferes, Rio de Janeiro, Brasil.

\begin{tabular}{|c|c|c|}
\hline & $\mathrm{n}$ & $\%$ \\
\hline Agricultores entrevistados & 55 & 100,0 \\
\hline Homens & 52 & 95,0 \\
\hline Mulheres & 3 & 5,0 \\
\hline \multicolumn{3}{|l|}{ Faixa etária (em anos) } \\
\hline Até 20 & 2 & 4,0 \\
\hline $21-40$ & 33 & 60,0 \\
\hline $41-60$ & 16 & 29,0 \\
\hline Mais de 60 & 4 & 7,0 \\
\hline \multicolumn{3}{|l|}{ Escolaridade } \\
\hline Nunca freqüentaram a escola & 15 & 27,0 \\
\hline Já freqüentaram a escola & 40 & 73,0 \\
\hline Até a 1a série do primeiro grau & 3 & 8,0 \\
\hline Até a 2a série do primeiro grau & 11 & 28,0 \\
\hline Até a 3a série do primeiro grau & 11 & 28,0 \\
\hline Até a 4 ạ série do primeiro grau & 9 & 23,0 \\
\hline Até a 5a série do primeiro grau & 1 & 2,0 \\
\hline Até a 6a série do primeiro grau & 1 & 2,0 \\
\hline Até a 7ạ série do primeiro grau & 1 & 2,0 \\
\hline Primeiro grau completo & 1 & 2,0 \\
\hline Segundo grau incompleto & 2 & 5,0 \\
\hline \multicolumn{3}{|l|}{ Situação na lavoura } \\
\hline Meeiros & 22 & 40,0 \\
\hline Proprietários & 21 & 38,0 \\
\hline Arrendatários & 4 & 7,0 \\
\hline Ocupantes & 4 & 7,0 \\
\hline Empregados & 2 & 4,0 \\
\hline Arrendatários e/ou Proprietários & 1 & 2,0 \\
\hline Sócios na lavoura & 1 & 2,0 \\
\hline \multicolumn{3}{|l|}{$\begin{array}{l}\text { Tempo de trabalho como } \\
\text { agricultor (em anos) }\end{array}$} \\
\hline Até 10 & 6 & 11,0 \\
\hline $11-20$ & 12 & 22,0 \\
\hline $21-30$ & 17 & 31,0 \\
\hline $31-40$ & 11 & 20,0 \\
\hline $41-50$ & 6 & 11,0 \\
\hline $51-60$ & 3 & 5,0 \\
\hline
\end{tabular}


Inseticidas usados no Município de Paty do Alferes, Rio de Janeiro, Brasil.

\begin{tabular}{|c|c|c|c|c|}
\hline Grupo químico & $\begin{array}{l}\text { Produto } \\
\text { comercial }\end{array}$ & $\begin{array}{l}\text { Substância } \\
\text { química básica }\end{array}$ & $\begin{array}{l}\text { Classe } \\
\text { toxicológica }\end{array}$ & $\begin{array}{l}\text { Lavouras em que } \\
\text { foram encontrados }(\%)^{\star}\end{array}$ \\
\hline \multirow[t]{7}{*}{ Organofosforado } & Tamaron & Metamidofos & 1 & $29(53,0)$ \\
\hline & Hamidop & Metamidofos & 1 & $19(35,0)$ \\
\hline & Elsan & Fentoato & I & $3(6,0)$ \\
\hline & Kilval & Vamidotion & II & $12(22,0)$ \\
\hline & Ortho Naled & Naled & II & $1(2,0)$ \\
\hline & Sumithion & Fenitrotion & II & $2(4,0)$ \\
\hline & Orthene & Acefato & III & $5(9,0)$ \\
\hline \multirow[t]{3}{*}{ Carbamato } & Diafuran & Carbofurano & 1 & $2(4,0)$ \\
\hline & Cartap & Cartap & II & $1(2,0)$ \\
\hline & Sevin & Carbaril & II & $2(4,0)$ \\
\hline \multirow[t]{8}{*}{ Piretróide } & Baytroid & Ciflutrin & 1 & $3(6,0)$ \\
\hline & Sumidan & Alfa Fenvalerato & 1 & $2(4,0)$ \\
\hline & Ambush & Permetrina & II & $17(31,0)$ \\
\hline & Decis & Deltametrina & II & $10(18,0)$ \\
\hline & Ripcord & Cipermetrina & II & $6(11,0)$ \\
\hline & Corsair & Permetrina & II & $5(9,0)$ \\
\hline & Nor-trin & Cipermetrina & II & $2(4,0)$ \\
\hline & Bulldock & Betaciflutrin & II & $1(2,0)$ \\
\hline Outros & Vertimec & Abamectina & III & $33(60,0)$ \\
\hline
\end{tabular}

* Total de lavouras visitadas $=55$.

Tabela 3

Fungicidas e acaricidas usados no Município de Paty do Alferes, Rio de Janeiro, Brasil.

\begin{tabular}{|c|c|c|c|c|}
\hline Pesticida & $\begin{array}{l}\text { Produto } \\
\text { comercial }\end{array}$ & $\begin{array}{l}\text { Substância } \\
\text { química básica }\end{array}$ & $\begin{array}{l}\text { Classe } \\
\text { toxicológica }\end{array}$ & $\begin{array}{l}\text { Lavouras em que } \\
\text { foram encontradas }(\%)^{\star}\end{array}$ \\
\hline \multirow[t]{15}{*}{ Fungicida } & Daconil & Clorotalonil & 1 & $26(47,0)$ \\
\hline & Dacostar & Clorotalonil & 1 & $1(2,0)$ \\
\hline & Rubigan & Fenarimol & ॥ & $7(13,0)$ \\
\hline & Dithane & Mancozeb & III & $24(44,0)$ \\
\hline & Manzate & Mancozeb & III & $11(20,0)$ \\
\hline & Orthocide & Captan & III & $8(15,0)$ \\
\hline & Curzate & Cimoxanil & III & $4(7,0)$ \\
\hline & Benlate & Benomil & III & $3(6,0)$ \\
\hline & Cerconil & Clorotalonil & III & $1(2,0)$ \\
\hline & Cobre Sandoz & Óxido cuproso & IV & $11(20,0)$ \\
\hline & Funguran & Oxicloreto de cobre & IV & $12(22,0)$ \\
\hline & Cuprogarb & Oxicloreto de cobre & IV & $4(7,0)$ \\
\hline & Microzol & Enxofre & IV & $3(6,0)$ \\
\hline & Cercobin & Tiofanato metílico & IV & $2(4,0)$ \\
\hline & Thiovit & Enxofre & IV & $1(2,0)$ \\
\hline \multirow[t]{2}{*}{ Acaricida } & Tedion & Tetradifon & III & $3(6,0)$ \\
\hline & Kumulus-s & Enxofre & IV & $3(6,0)$ \\
\hline
\end{tabular}

* Total de lavouras visitadas $=55$. 
Equipamento de proteção

e medidas de higiene

Dos entrevistados, $92 \%$ informaram não usar qualquer tipo de equipamento de proteção individual para preparar e/ou aplicar os pesticidas. Esta situação tem sido observada em estudos realizados em outras regiões do nosso país $7,9,11$. Os motivos alegados para não usar equipamentos de proteção, i.e. "falta de costume" (29\%), "são desconfortáveis" (22\%), "são quentes” (18\%), "dificultam o trabalho” (16\%), "custam caro" (16\%), também foram semelhantes aos descritos em outros levantamentos 13 . Quanto às medidas de higiene pessoal, $98 \%$ relataram que lavam as mãos e $77 \%$ informaram que tomam banho logo após a aplicação e/ou preparo de pesticidas. $77 \%$ dos entrevistados relataram que as roupas que vestem quando preparam e/ou aplicam os pesticidas são separadas das roupas da família para lavagem. Dos agricultores que lavam em separado a roupa usada na aplicação e/ou no preparo do pesticida, $48 \%$ informaram que o fazem para evitar contaminação com o veneno e outros $36 \%$ por causa do "forte mau cheiro" que impregna o tecido. $12 \%$ lavam a roupa no local de trabalho.

\section{Armazenagem e destino}

das embalagens vazias

Dos entrevistados, $52 \%$ guardam as embalagens de agroquímico em local trancado. Não existe na região uma prática única com relação ao descarte das embalagens de pesticidas. Dos 55 entrevistados, $15 \%$ guardam para posterior reciclagem a ser realizada pela prefeitura, $13 \%$ enterram, $11 \%$ queimam, $8 \%$ deixam na própria lavoura e $6 \%$ reúnem os restos e jogam na mata. $45 \%$ dos entrevistados disseram utilizar mais de uma forma de descarte: $23 \%$ queimam (plástico) ou enterram (vidro), 6\% queimam ou reúnem os restos e jogam na mata (vidro), $6 \%$ queimam ou deixam na lavoura (vidro), entre outros.

\section{Orientação e assistência técnica}

Entre os entrevistados, $62 \%$ disseram não ter recebido assistência técnica em 1996, mas $11 \%$ receberam visita da Empresa de Assistência Técnica e Extensão Rural do Estado do Rio de Janeiro (EMATER-RIO), 8\% do vendedor de produtos agrícolas da região e $4 \%$ da Empresa Brasileira de Pesquisa Agropecuária (EMBRAPA). Outros $4 \%$ receberam visita de um engenheiro agrônomo autônomo e $2 \%$ da Secretaria de Agricultura do município. $6 \%$ não souberam informar. Com relação à compra dos pesticidas, $28 \%$ compraram com base na indicação do vendedor, $25 \%$ tiveram indicação de outro agricultor e $21 \%$ do dono da terra onde trabalham. O restante fez a escolha dos pesticidas de acordo com a indicação da EMATER-RIO (6\%), de um agrônomo (4\%) ou sócio (4\%) e $8 \%$ não tiveram nenhum tipo de indicação. $4 \%$ não souberam informar. Quanto ao cálculo da quantidade de pesticida usada por aplicação, 57\% o fizeram de acordo com o rótulo, mas $13 \%$ dos entrevistados não sabiam informar as concentrações de pesticidas usadas. Os outros agricultores calculavam após receber orientação do vendedor (8\%), de outro agricultor $(8 \%)$, de um agrônomo (4\%) ou da EMATER-RIO (2\%). 8\% calcularam a quantidade de pesticida necessária para cada aplicação por experiência própria e $68 \%$ disseram ter aprendido a usar pesticidas com outro agricultor.

\section{Morbidade referida}

Dos entrevistados, $62 \%$ informaram já ter "passado mal" ao preparar e/ou aplicar pesticidas. Os sintomas citados pelos entrevistados são relacionados na Tabela 4, destacando-se: dor de
Tabela 4

Sintomas que os agricultores relataram ter apresentado durante e/ou logo após a preparação e/ou aplicação de pesticidas na lavoura. Paty do Alferes, Rio de Janeiro, Brasil.

\begin{tabular}{lrr}
\hline & $\mathbf{n}$ & $\%$ \\
\hline Agricultores entrevistados & 55 & 100,0 \\
Relataram já ter "passado mal" & 34 & 62,0 \\
Relataram nunca ter "passado mal" & 21 & 38,0 \\
Agricultores que apresentaram & 34 & 100,0 \\
sintomas & & \\
Dor de cabeça & 24 & 71,0 \\
Enjôo & 17 & 50,0 \\
Diminuição da visão & 13 & 38,0 \\
Vertigem/tonteira & 12 & 35,0 \\
Irritação da pele & 10 & 29,0 \\
Perda de apetite & 8 & 24,0 \\
Tremores & 5 & 15,0 \\
Vômitos & 5 & 15,0 \\
Crise alérgica (espirro) & 2 & 6,0 \\
Diarréia & 2 & 6,0 \\
Dores no peito & 2 & 6,0 \\
Secura na garganta & 1 & 3,0 \\
Nervosismo & 1 & 3,0 \\
& &
\end{tabular}


cabeça (71\%), enjôo (50\%), diminuição da visão (38\%), vertigem/tonteira (35\%), irritação da pele $(29 \%)$, perda de apetite $(24 \%)$, tremores (15\%), vômitos (15\%), crise alérgica (6\%), diarréia $(6 \%)$, dores no peito $(6 \%)$, secura na garganta (3\%) e nervosismo (3\%). A nossa observação in loco sugere que o entrevistado ("líder" ou "dono da terra") não diferia dos demais trabalhadores quanto ao contato, hábitos e cuidados no manuseio dos pesticidas. Assim sendo, possivelmente este quadro de morbidade referida pode ser extrapolado para o conjunto de trabalhadores de Paty do Alferes.

Dos 34 lavradores que "passaram mal" enquanto trabalhavam com pesticidas, $21 \%$ procuraram atendimento médico em posto de saúde ou hospital e $24 \%$ informaram não ter tomado qualquer providência. A automedicação com leite (42\%), analgésicos $(27 \%)$, chás medicinais (9\%) e azeite doce $(6 \%)$ aparece entre as iniciativas referidas pelos agricultores. Entre os 34 indivíduos que relataram ter "passado mal”, $21 \%$ não souberam identificar os produtos que usavam, $30 \%$ mencionaram estar usando Tamaron $\AA, 9 \%$ o Elsan ${ }^{\circledR}, 6 \%$ o Ortho Hamidop ${ }^{\circledR}, 6 \%$ o Kilval ${ }^{\circledR}, 3 \%$ o Hostathion ${ }^{\circledR}$ e $3 \%$ o Meothrin ${ }^{\circledR}$, todos inseticidas do grupo dos organofosforados da classe toxicológica I, com exceção do Kilval ${ }^{\circledR}$ (classe II). Rubigan ${ }^{\circledR}$ e Decis ${ }^{\circledR}$ (classe II) foram citados três vezes e Daconil@ (classe I), Ambush ${ }^{\circledR}$ e Kilval ${ }^{\circledR}$ (classe II) foram citados duas vezes.

Os produtos que estavam sendo usados pelos lavradores quando procuraram atendimento médico foram: Hostathion ${ }^{\circledR}$ (classe I), Daconil ${ }^{\circledR}$ (classe I), Tamaron ${ }^{\circledR}$ (classe I), Ortho Hamidop ${ }^{\circledR} 600$ (classe I), Rubigan ${ }^{\circledR}$ (classe II), Ambush ${ }^{\circledR}$ (classe II), Decis 25CE® (classe II), Kilval ${ }^{\circledR}$ (classe II) e Vermitec ${ }^{\circledR}$ (classe III). Na maioria dos casos (79\%), os entrevistados relataram que voltaram e/ou ainda trabalham com os mesmos produtos que usavam quando "passaram mal".

Em todas as 55 lavouras visitadas no Município de Paty do Alferes são usados pesticidas, em particular os inseticidas e fungicidas. Entre os inseticidas utilizados com maior freqüência encontra-se a abamectina, os organofosforados metamidofos e vamidotion e os piretróides permetrina, cipermetrina e deltametrina. Os fungicidas mais usados são o ditiocarbamato mancozeb, o clorotalonil e os diferentes produtos à base de cobre.

Particularmente preocupante é o uso freqüente dos inseticidas organofosforados metamidofos e vamidotion (classes toxicológicas I e II), já que estes compostos são bem absorvidos por via dérmica, e $92 \%$ dos lavradores relata- ram que não usam qualquer tipo de equipamento de proteção individual quando preparam e aplicam pesticidas. A cena típica é o lavrador com as vestes habituais de trabalho i.e. boné ( $81 \%)$, calça comprida ( $74 \%$ ) e camisa de mangas curtas (58\%), descalço (49\%) e sem luva ou qualquer proteção para a face - segurando a mangueira com que aplica o pesticida (conhecido na região como "remédio para plantas" ou "veneno"). Nestas condições, a porta de entrada para os organofosforados é uma área descoberta de pele que corresponde a aproximadamente $30 \%$ da superfície total do corpoi.e. cabeça e pescoço: 6,8\%, braço e antebraço: $16,4 \%$ e mãos: $6,9 \%$ da superfície corporal, para o homem de $175 \mathrm{~cm}$ de altura, $78 \mathrm{~kg}$ de peso e $1,92 \mathrm{~m}^{2} \mathrm{de}$ área corporal total (estimativa baseada em dados de Spear et al. 14). Portanto, é provável que a exposição ocupacional aos inseticidas organofosforados seja importante na região.

Dentre os $62 \%$ dos entrevistados que relataram ter "passado mal" durante e/ou logo após o preparo e/ou aplicação de pesticidas, $21 \%$ tiveram de procurar atendimento médico no posto de saúde ou hospital. Entre os sintomas referidos merecem destaque a "dor de cabeça”, o "enjôo", a "tonteira/vertigem”, a "irritação da pele" e a "diminuição da visão". A “irritação da pele” é um sintoma local que, em menor ou maior grau, pode ser causado por quase todos os pesticidas encontrados na região. Os outros sintomas ("dor de cabeça”, "enjôo", "tonteira/vertigem" e "diminuição da visão”) são pouco específicos, mas são compatíveis com intoxicações agudas leves ou moderadas causadas por inibidores da colinesterase (e.g. organofosforados). Episódios de intoxicação leve ou moderada por organofosforados podem, inclusive, ser confundidos com estados gripais. É interessante notar que, em mais da metade dos casos (51\%) em que os lavradores identificaram os pesticidas que usavam quando "passaram mal", foram citados inseticidas organofosforados da classe toxicológica I.

Após análise dos dados apresentados neste trabalho, alguns aspectos tornam-se evidentes como, por exemplo, o uso intenso de pesticidas organofosforados de classe toxicológica I (extremamente tóxicos) e a falta de uso de equipamentos de proteção individual pelos agricultores que preparam e aplicam estes produtos. Nestas condições pode-se antecipar que a exposição por via dérmica é importante e medidas relativamente simples e baratas, como o uso de luvas e camisas de manga comprida, poderiam desde já reduzi-las substancialmente. 


\section{Resumo}

Este trabalho é parte de um estudo mais amplo sobre as conseqüências para a saúde da exposição a pesticidas. Em 1997, no Município de Paty do Alferes, Rio de Janeiro, 55 agricultores foram entrevistados sobre o uso de pesticidas, equipamentos de proteção e medidas de higiene, ocorrência de intoxicações, destino das embalagens vazias e o tipo de orientação técnica recebida pelos usuários destes produtos. Os pesticidas mais usados foram inseticidas como a abamectina, os compostos organofosforados e os piretróides, e os fungicidas como o mancozeb, o clorotalonil e produtos à base de cobre. Entre os trabalhadores envolvidos no preparo elou aplicação de pesticidas, 92\% informaram não usar qualquer tipo de equipamento de proteção individual. $62 \%$ dos agricultores entrevistados informaram já ter "passado mal" ao preparar ou aplicar pesticidas. Os sintomas mais freqüentemente citados foram dor de cabeça, enjôo, vômitos, vertigem,irritação da pele e visão embaçada. Destes agricultores, $21 \%$ necessitaram de assistência médica e em mais da metade dos casos (51\%), em que os lavradores identificaram os pesticidas que usavam quando "passaram mal", foram citados inseticidas organofosforados da classe toxicológica I.

Exposição Ocupacional; Praguicidas; Compostos Organofosforados; Saúde Ocupacional

\section{Referências}

1. World Health Organization/United Nations Environment Programme. Public health impact of pesticides used in agriculture. Geneva: World Health Organization/United Nations Environment Programme; 1990.

2. Pimentel D. Diversification of biological control strategies in agriculture. Crop Prot 1991; 10:243-53.

3. Forget G. Pesticides: necessary but dangerous poisons. International Development Research Center Report 1989; 18:4-5.

4. Weir S, Minton N, Murray V. Organophosphate poisoning: The UK National Poisons Unit experience during 1984-1987. In: Ballantyne B, Barrs TC, editors. Clinical and experimental toxicology of organophosphates and carbamates. Oxford: Butterworth-Heinemann; 1992. p. 463-70.

5. Jeyaratnam J. Occupational health issues in developing countries. Environ Res 1993; 60:207-12.

6. Garcia EG. Pesticides control experiences in Brazil Pesticide Safety 1997; 2:5.

7. Machado Neto JG, Matuo T, Matuo YK. Semiquantitative evaluation of dermal exposure to granulated insecticides in coffee (Coffea arábica L.) crop and efficiency of individual protective equipment. Bull Environ Contam Toxicol 1996; 57:946-51

8. Garcia EG, Almeida WE. Exposição dos trabalhadores rurais aos agrotóxicos no Brasil. Revista Brasileira de Saúde Ocupacional 1991; 72:7-11.

\section{Colaboradores}

I. Delgado contribuiu nas etapas de aplicação dos questionários, de análise dos dados obtidos e na elaboração do texto do artigo. F. Paumgartten participou da análise dos dados obtidos nos questionários e da elaboração do texto do artigo.

\section{Agradecimentos}

Este trabalho foi financiado com recursos do PADCTFINEP (CIAMB). Francisco José Roma Paumgartten recebe bolsa de pesquisa do Conselho Nacional de Desenvolvimento Científico e Tecnológico.
9. Oliveira-Silva JJ, Alves SR, Meyer A, Perez F, Sarcinelli PN, Mattos RCOC, et al. Influência de fatores socioeconômicos na contaminação por agrotóxicos, Brasil. Rev Saúde Pública 2001; 35: 130-5.

10. Koifman S, Koifman RJ, Meyer A. Human reproductive system disturbances and pesticide exposure in Brazil. Cad Saúde Pública 2002; 18:435-45.

11. Waichman AV, Rombke J, Ribeiro MO, Nina NC. Use and fate of pesticides in the Amazon State, Brazil: risk to human health and the environment. Environ Sci Pollut Res Int 2002; 9:423-8.

12. Pereira LC, Meneguelli NA, Lima W, Fernandes TAG, Tôsto SG. Perfil agrossocioeconômico e estratos de produtividade da cultura do tomate na microbacia do Córrego da Cachoeira, Paty do Alferes - Rio de Janeiro. Rio de Janeiro: Centro Nacional de Pesquisa de Solos, Empresa Brasileira de Pesquisa Agropecuária; 1996.

13. Coutinho JAG, Freitas EAV, Cavalcanti MAS, Ferry RV, Lins LGC, Santos JA, et al. Uso de agrotóxicos no município de Paty do Alferes: um estudo de caso. Cadernos de Geociências 1994; 10:23-31.

14. Spear RC, Popendorf WJM, Leffingwell JT. Field workers' response to weathered residues of parathion. J Occup Med 1977; 19:406-10.

Recebido em 07/Jan/2003

Versão final reapresentada em 18/Jun/2003 Aprovado em 16/Out/2003 